\title{
Phytobacterial Type III Effectors HopX1, HopAB1 and HopF2 Enhance Sense-Post-Transcriptional Gene Silencing Independently of Plant R Gene-Effector Recognition
}

\author{
Panagiotis F. Sarris, ${ }^{1,2}$ Shang Gao, ${ }^{3}$ Konstantinos Karademiris, ${ }^{2}$ Hailing Jin, ${ }^{3}$ Kriton Kalantidis,,${ }^{1,2}$ and \\ Nickolas J. Panopoulos ${ }^{1,2}$ \\ 'Institute of Molecular Biology and Biotechnology, Foundation for Research and Technology, Hellas, PO Box 1527, Heraklion \\ 71110, Crete, Greece; ${ }^{2}$ Department of Biology, University of Crete, 71409 Heraklion, Greece; ${ }^{3}$ Department \\ of Plant Pathology and Microbiology, Center for Plant Cell Biology and Institute for Integrative Genome Biology, University \\ of California, Riverside 92521, U.S.A.
}

Submitted 16 January 2011. Accepted 23 March 2011.

\begin{abstract}
Plant- and animal-pathogenic bacteria deploy a variable arsenal of type III effector proteins (T3EP) to manipulate host defense. Specific biochemical functions and molecular or subcellular targets have been demonstrated or proposed for a growing number of T3EP but remain unknown for the majority of them. Here, we show that transient expression of genes coding certain bacterial T3EP (HopAB1, HopX1, and HopF2), which did not elicit hypersensitive response (HR) in transgenic green fluorescent protein (GFP) Nicotiana benthamiana 16C line, enhanced the sense posttranscriptional gene silencing (S-PTGS) triggered by agrodelivery of a GFP-expressing cassette and the silencing enhancement could be blocked by two well-known viral silencing suppressors. Further analysis using genetic truncations and site-directed mutations showed that the receptor recognition domains of HopAB1 and HopX1 are not involved in enhancing silencing Our studies provide new evidence that phytobacterial pathogen T3EP manipulate the plant small interfering RNA pathways by enhancing silencing efficiency in the absence of effector-triggered immunity signaling and suggest that phytopathogenic bacterial effectors affect host RNA silencing in yet other ways than previously described.
\end{abstract}

Plants have evolved a number of efficient defense responses, both passive and active, against microbial and viral pathogens which, in turn, deploy appropriate strategies to overcome the various levels of plant defense (Chisholm et al. 2006; Gohre and Robatzek 2008; Jones and Dangl 2006; Voinnet 2001). An emerging consensus view is that pathogens deploy type III effector proteins (T3EP) as a main mechanism to suppress active defense of their hosts. One branch of active defense is triggered by the recognition of pathogen-associated molecular patterns (PAMPs) by host cell transmembrane proteins that function as pattern recognition receptors (PRR) which, in turn, activate PAMP-triggered immunity (PTI). In compatible plant-bacte-

Corresponding author: N. J. Panopoulos; Telephone: +302810394369 , Fax: +30 2810 394408; E-mail: panopoul@imbb.forth.gr

* The $\boldsymbol{e}$-Xtra logo stands for "electronic extra" and indicates that six supplementary figures, one supplementary table, and supplementary data analysis are published online. Also, Figure 7 appears in color online. rium interactions, where disease develops, pathogens both avoid recognition by host resistance $(R)$ genes and actively suppress PTI. Accumulating evidence suggests that bacterial pathogens accomplish this by delivering selected sets of proteins, termed T3EP, often directly to the plant cell interior via the type III secretion system (T3SS). Another branch of active defense, called effector-triggered immunity (ETI), is triggered in incompatible interactions, where disease does not develop, as a result of the functional recognition between bacterial avirulence ( $a v r$ ) genes and plant $R$ genes ("gene-for-gene" systems) (Flor 1947). This form of defense is often expressed as rapid localized necrosis of cells contacting the pathogen or those in their immediate vicinity (hypersensitive response [HR]) (Chisholm et al. 2006; Dangl and Jones 2001; Jones and Dangl 2006; Nicaise et al. 2009; Tampakaki et al. 2010).

Accumulating evidence suggests that some nucleotide-binding site leucine-rich repeat (NBS-LRR) receptors coded by $R$ genes may detect Avr proteins in different ways: some by direct binding, others as complexes with host proteins, and others via their modification of host proteins (Ellis et al. 2007; Jones and Dangl 2006; Wulff et al. 2009). Avr proteins of bacterial pathogens constitute a subset of T3EP and the manifestation of the bacterial avirulence phenotype requires a functional T3SS (Chisholm et al. 2006). Importantly, in the absence of $R-$ avr recognition, Avr proteins often promote virulence. Thus, these T3EP function as "double agents" in plant-microbe interactions, acting as virulence factors in one host genotype and as avirulence factors in another (Alfano and Collmer 2004; Tsiamis et al. 2000). It is also becoming increasingly apparent that the majority of phytobacterial T3EP can suppress either PTI triggered by various PAMPs, ETI triggered by other effectors, or both (Abramovitch and Martin 2005; Abramovitch et al. 2003; Espinosa and Alfano 2004; Guo et al. 2009; Huang et al. 1988; Mudgett 2005; Nomura et al. 2005), and some inhibit cell-wall-based defense response such as callose deposition (Hauck et al. 2003).

RNA silencing is an important mechanism of gene regulation mediated by small RNAs in plants and other eukaryotes and is implemented via small interfering (si)RNAs of different origins and modes of biogenesis. Recent studies showed that this mechanism is also involved in the manipulation of plant immune responses by bacterial pathogens (Katiyar-Agarwal and Jin 2010). For example, Dunoyer and colleagues (2006) 
showed that siRNAs corresponding to T-DNA oncogenes initially accumulate in Agrobacterium tumefaciens-infected tissues and that loss-of-function RNA-dependent RNA polymerase 6 (rdr6) mutants of Arabidopsis thaliana are hypersusceptible to A. tumefaciens tumorigenesis. They suggested that successful infection relies on a potent antisilencing state established in tumors, whereby siRNA synthesis is specifically inhibited. This inhibition has only modest side effects on the micro (mi)RNA pathway, shown to be essential for disease development. Katiyar-Agarwal and associates (2006) reported that an endogenous "natural" siRNA (nat-siRNAATGB2) is specifically induced in Arabidopsis thaliana during the incompatible interaction with Pseudomonas syringae pv. tomato DC3000 carrying avr gene (T3EP) avrRpt2, which specifies gene-for-gene resistance in RPS2 hosts. The authors concluded that the small RNA pathway components, RDR6 and HYL1, a doublestranded RNA binding protein that interacts with DCL1, are required for RPS2-mediated resistance (Katiyar-Agarwal et al. 2006). This nat-siRNA seems to contribute to RPS2-mediated race-specific incompatibility (disease resistance) by repressing the pentatricopeptide repeats protein-coding gene, a putative negative regulator of the RPS2 resistance pathway (KatiyarAgarwal et al. 2006). Navarro and colleagues (2006) reported the induction of a plant miRNA, miR393, by a bacterial flagellin-derived peptide, the elicitor flg22. This miRNA targets messenger RNAs for the F-box auxin receptor TIR1 and its close paralogs, AFB2 and AFB3, and downregulates auxin responses which, in turn, restricts $P$. syringae pv. tomato growth in planta. In further studies, Katiyar-Agarwal and associates (2007) also identified another class of small RNAs, long siRNAs (lsiRNAs) in Arabidopsis thaliana which are 30 to 40 nucleotides long and seem to be induced by pathogen infection. One of them, AtlsiRNA-1, is specifically induced in incompatible $P$. syringae pv. tomato interactions mediated by the avrRpt 2 gene. Fahlgren and associates (2007) also reported the differential regulation of several mature miRNAs, including miR393, in response to Pto DC3000 hrc $C^{-}$mutant and flg22. Finally, Navarro and colleagues (2008) reported that HopAB2 and other $P$. syringae effectors suppress transcriptional activation, biogenesis, stability, or activity of some PAMP-responsive miRNAs. The HopAB2 effector suppresses miR393a and miR393b transcription independently of its E3-ligase activity, as is also the case for HopAB2-mediated suppression of the PAMP (flg22)-responsive basal defense marker gene FRK1 (He et al. 2006). The authors proposed that phytopathogenic bacteria, like plant viruses, have evolved mechanisms to suppress RNA silencing in order to cause disease.

Except in the study by Navarro and associates (2008), in the other experimental systems with Pseudomonas effectors, $R$ gene-specific effector recognition was operative (via the RPS2avrRpt 2 gene pair), thus mirroring "incompatible" pathosystem settings. Therefore, a role for silencing in compatible Pseudomonas spp.-plant interactions, where ETI signaling is not expected to be operational, remains an open question.

In a routine screening of proven and putative bacterial T3EP from various plant-pathogenic bacterial strains for HR-inducing ability in a Nicotiana benthamiana green fluorescent protein (GFP)-expressing line (16C), we identified several T3EP that interfered with GFP silencing triggered by transient coexpression of the $g f p$ gene. These T3EP do not trigger the HR in this host and are able to suppress this reaction when it is triggered by other effectors on tobacco and Arabidopsis, as well as the programmed cell death (PCD) in plants and yeast (Jamir et al. 2004). In this report, we present evidence that these T3EP enhance the activity of specific RNA silencing pathways when delivered by transient expression. Furthermore, we propose the use of silencing assays in functional genomics of phytobacte- rial effectors and as an additional means for assigning cellular roles to T3EP, which will be especially useful for those with no other known or suggested biochemical, molecular, or cellular function.

\section{RESULTS}

\section{HopAB1, HopAB2, HopX1, and HopF2 T3EP enhance GFP silencing.}

In preliminary experiments, we examined whether the effectors that did not trigger $\mathrm{HR}$ in our model host $N$. benthamiana line 16C (HopAB1, HopX1, HopF2, and HopAB2, also known as VirPphA, AvrPphE, AvrPphF, and AvrPtoB, respectively) and the corresponding $35 S::$ effector cassettes were biologically functional by carrying out HR assays on common bean genefor-gene differentials or on nonhost plants as appropriate for each effector (Flor 1947; Jackson et al. 1999; Tsiamis et al. 2000) (data not shown) and by Northern analysis of RNA extracts from $N$. benthamiana 16C leaf tissue with effector-specific probes following agroinfiltration (Supplementary Fig. S5). The HopX1 and HopAB1 effectors elicited HR-like necrosis on common bean, as did the HopF2 and HopAB1 on several nonhost plants, when delivered by the Agrobacterium system.

The phenotypes of these effectors in $N$. benthamiana $16 \mathrm{C}$ leaves were as follows. The first three effectors did not elicit HR-like necrosis or other macroscopic reactions by this delivery method, except for progressive chlorosis or senescence of the infiltrated area after the 10th day postagroinfiltration (data not shown). The HopAB2 effector elicited progressive tissue collapse starting at day 4 after agroinfiltration. The nature and basis of this reaction is not obvious. HopAB1 and HopAB2 share $55 \%$ sequence identity and have similar domain structure but differ in several respects (Supplementary Fig. S4; also discussed below). It is not known which of these differences are responsible for the tissue collapse elicited by HopAB2, as opposed to HopAB1, in agroinfiltrated $N$. benthamiana $16 \mathrm{C}$ leaves.

Based on these experiments, the HopAB1, HopX1, and HopF2 effectors were subsequently examined for their ability or inability to affect the silencing mechanism on $N$. benthamiana 16C, a transgenic line expressing the mGFP5-ER protein constitutively (Ruiz et al. 1998), which is commonly used as an indicator plant for silencing assays (Voinnet et al. 2000). Sense post-transcriptional gene silencing (S-PTGS) was induced by transient expression of the $g f p$ gene via agrodelivery of a $35 S::$ GFP cassette. Effector delivery was accomplished by infiltration of 1:1 mixtures of agrobacteria (prepared just before infiltration), with one strain carrying the $35 S::$ GFP and the other the $35 S::$ T3EP constructs on binary vectors, as described by Voinnet and associates (2000) and Guo and Ding (2002). Agroinfiltrated leaves were examined daily for any visible effect of various T3EP on the GFP fluorescence intensity under UV light and differences between T3EP-treated and control panels were scored. For verification, the experiments were repeated at least 10 times in different $N$. benthamiana $16 \mathrm{C}$ and wild-type (WT) plants and the results were highly reproducible. Normally, in $N$. benthamiana 16C transient GFP overexpression following agroinfiltration leads initially to strong GFP fluorescence in the agroinfiltrated areas, followed by gradual decrease to baseline levels over a period of several days, due to the triggering of the silencing process following transient GFP overexpression (Ruiz et al. 1998). In our experiments, GFP fluorescence of the effector-treated areas was strongly reduced compared with the empty vector controls, beginning at 3 to 4 days postinoculation (dpi), and differences were maximized by 6 dpi. This was observed with HopX1 and HopAB1 (from $P$. 
syringae pv. tomato DC3001 and P. syringae pv. phaseolicola 1449B, respectively) but not with HopX1m, a naturally occurring variant of the HopX1 T3EP family found in $P$. syringae pv. phaseolicola NPS3121 (Peet et al. 1986) that carries an IS5 insertion at the $3^{\prime}$ of its open reading frame that renders it nonfunctional in HR assays on resistant bean plants (Inoue and Takikawa 1999). With HopAB2, a reduction of GFP fluorescence compared with the empty vector controls was also observed at day 3 dpi (Supplementary Fig. S2) but the tissue collapse ensuing on the following day made GFP fluorescence assays at later days potentially unreliable.

\section{T3EP affect positively GFP-specific siRNA accumulation.}

The reduction in the GFP fluorescence following coinfiltration of agrobacteria carrying $35 S::$ effector gene and $35 S:: g f p$ cassettes (Fig. 1) was accompanied by changes in GFP-specific mRNA and siRNA levels as determined by Northern analysis (Fig. 2I, II, and III). Specifically, in HopX1- and HopAB1treated leaf panels, the GFP mRNA levels were reduced to approximately one-third of those detected in the empty vector control, and GFP-specific siRNA levels (measured by densitometric analysis of the specific Northern bands) were increased approximately threefold (Fig. 2I). No changes in GFP fluorescence, GFP mRNA, or GFP siRNA levels were seen in panels treated with the hopXIm allele (Fig. 2III). Similar results to HopX1 and HopAB1 were obtained with the HopF2 effector from P. syringae pv. tomato DC3001 (Supplementary Fig. S1). Based on these results, HopX1, HopAB1, and HopF2 appear to function as enhancers of GFP silencing under conditions in which the effectors do not trigger the HR.
Two viral RNA silencing suppressors reverse the T3EP enhancement effect.

To confirm that the phenomenon observed is silencing dependent, we performed coinfiltration and overlap-infiltration assays with agrobacteria carrying expression cassettes for two well-known viral silencing-suppressor proteins, plus agrobacteria carrying HopX1 and HopAB1 expression cassettes. Expression cassettes carrying the Turnip crinkle virus (TCV) silencing suppressor p38 (viral coat protein) (Thomas et al. 2003) and the Cymbidium ringspot tombusvirus (CymRSV) silencing suppressor p19 (Havelda et al. 2003) cloned in appropriate binary vectors behind a Cauliflower mosaic virus (CaMV) $35 \mathrm{~S}$ promoter were introduced in A. tumefaciens. Selected areas of N. benthamiana $16 \mathrm{C}$ leaf panels were infiltrated with binary mixtures of A. tumefaciens strains (1:1 ratio, prepared just before infiltration), with one strain carrying the $35 S::$ GFP and the other the $35 S::$ T3EP constructs. Adjacent areas were infiltrated with $1: 1$ mixtures of agrobacteria carrying binary plasmids with either the GFP or the viral silencing suppressor $35 \mathrm{~S}$ cassettes, such that the infiltrated areas partially overlapped (Chakravarthy et al. 2009; Oh and Collmer 2005). Infiltrated leaves were phenotypically screened and photographed under UV light at 6 dpi to observe the effect of the viral silencing suppressors on the T3EPinduced $g f p$ silencing enhancement effect (Fig. 3). In contrast to the silencing enhancement seen with the T3EP, a strong suppression of GFP silencing was observed in the overlapping portion of the infiltrated areas (Fig. 3). Northern analysis of the GFP mRNAs and GFP siRNAs showed that this suppression was reflected in the GFP mRNA and siRNA levels (i.e., overaccumulation of GFP mRNAs and absence of GFP siRNAs in the


Fig. 1. Effect of transient expression of hopX1, hopAB1, and hopX1m on green fluorescent protein (GFP) silencing in Nicotiana benthamiana 16C plants. A, GFP fluorescence assay. Mixtures (1:1) of agrobacteria carrying the expression cassettes or control plasmids (empty vector [EV]) indicated above the images were infiltrated in $N$. benthamiana $16 \mathrm{C}$ leaves photographed at 6 days postinoculation (dpi) under UV (A-I) and visible (A-II). Agroinfiltration was carried out as described (Hamilton et al. 2002). GFP fluorescence was monitored 4 and 6 dpi with a hand-held long-wavelength UV lamp. Plants were photographed with a NIKON COOLPIX 990 digital camera, under UV (A-I) and normal light (A-II) and pictures were processed using Adobe Photoshop CS2. B, Densitometric quantification of GFP fluorescence in infiltrated leaf areas, using the ImageJ program (developed at the United States National Institutes of Health). Fluorescence intensity values were determined after subtracting background fluorescence of noninfiltrated areas on the same leaf. Experiments were repeated at least 10 times on separate plants. 
presence of the two viral silencing suppressors) (Fig. 2I and II). The blocking effect of the viral suppressors on the GFP siRNA accumulation is a strong indication that the GFP silencing-enhancement phenotype induced by HopX1 and HopAB1 is silencing dependent. Overaccumulation of hopAB1, hopX1, and hopXIm mRNAs was also observed in the presence of the viral silencing suppressors.

\section{The 376- to 539-residue $\mathrm{C}$-terminal region} of HopAB1 is sufficient for silencing-enhancement activity.

The absence of HR necrosis manifestation in the $N$. benthamiana $16 \mathrm{C}$ system implies that functional $R$-avr recognition is not required for the enhancement of GFP silencing and GFP siRNA accumulation. Nevertheless, many T3EP are multifunctional proteins, endowed with both virulence and avirulence functions which, presumably, are implemented via functional interactions with different host proteins. Accordingly, we sought to further examine the specific effector domains or functionalities responsible for the silencing enhancement phenomenon. HopAB1 was first identified as a virulence factor coded in a large $P$. syringae pv. phaseolicola 1449B (race 7) plasmid and belongs to a gene family whose founding member is HopAB2 from $P$. syringae pv. tomato DC3000. HopAB2 is a well-characterized, multifunctional effector with three distinct domains, each with different assigned functions: the N-terminal domain (residues 1 to 307), a central domain (Rsb, residues 308 to 387), and a C-terminal domain (residues 387 to 553) (Abramovitch and Martin 2005; Abramovitch et al. 2003; Xiao et al. 2007). The N-terminal domain interacts with the Pto kinase, a plant resistance protein, to activate Pto- or Prf-dependent immunity against $P$. syringae pv. tomato in resistant (Pto) tomato genotypes and promote ethylene-associated virulence in susceptible (pto) tomato lines by interacting with an unknown protein (Xiao et al. 2007). The Rsb domain interacts with the Fen kinase (fenthion sensitivity) protein and these interactions are responsible for activating the plant immune response on certain tomato cultivars (Abramovitch et al. 2003; Janjusevic et al. 2006). The region comprising the Rsb plus the C-terminal domain (residues 308 to 553) is sufficient to suppress HR-based PCD. Deletion of the C-terminal domain allows the amino-terminal two-domain region of HopAB2 (HopAB2 $2_{1-387}$ ) to be detected by certain tomato cultivars, leading to immunity-associated PCD. The final 44 residues of the protein are necessary for both Pto- and Fen-mediated HRbased PCD in tomato (Abramovitch et al. 2003). The C-terminal shares three-dimensional structural homology with RINGfinger/U-box E3 Ub ligases (eukaryotic E3 ubiquitin ligases), exhibits E3 ligase activity in vitro (Janjusevic et al. 2006), and ubiquitinates the Fen protein, promoting its degradation in a proteasome-dependent manner and leading to disease susceptibility in Fen-expressing tomato lines (Rosebrock et al. 2007).

We sought to identify specific domains of HopAB2 involved in the putative silencing phenotype in the $N$. benthamiana $16 \mathrm{C}$ line, taking advantage of functionally characterized mutants of this effector, recording GFP fluorescence measurements at 3 dpi. One of the mutants tested $(\Delta 4)$ retains the Rsb and ubiquitin E3 ligase domains (Abramovitch et al. 2003) while the other, F489A, carries a site-directed substitution (F489A) in the full-length HopAB2 protein which strongly reduces its E3ligase activity toward Fen (Janjusevic et al. 2006). Expression cassettes of these mutants cloned in the binary vector pBTEX in the Agrobacterium sp. strain GV2260 were tested on $N$. benthamiana 16C leaves. With the F489A mutant, GFP fluorescence differences were unreliable or impossible to record,
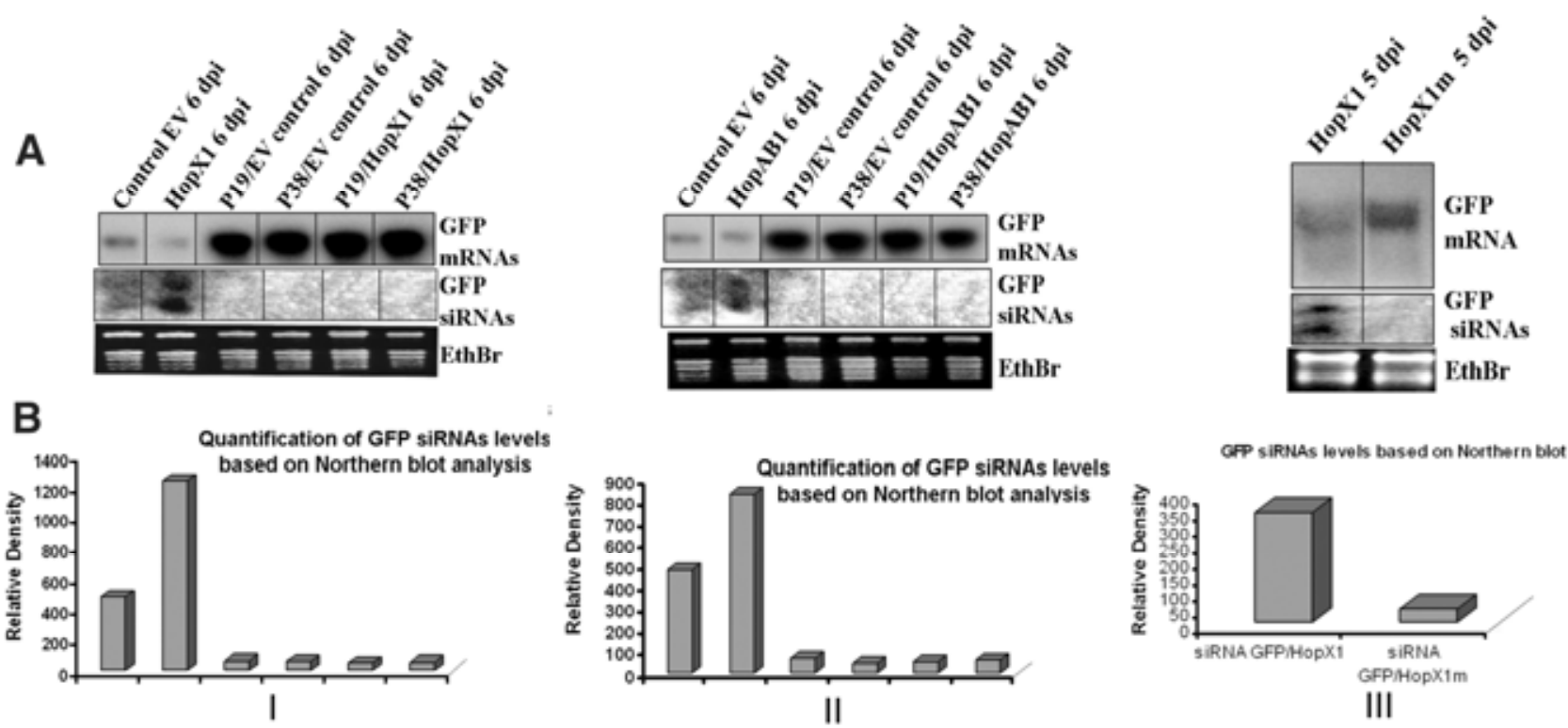

Fig. 2. Transient expression of hopX1, hopAB1 enhances the RNA-mediated green fluorescent protein (GFP) silencing, in contrast to the nonfunctional hopX1 allele (hopX1m) from Pseudomonas syringae pv. phaseolicola NPS3121. Mixtures of agrobacteria (1:1) carrying the effector or viral protein expression cassettes oir empty vector (EV) control plasmids indicated above the lanes were infiltrated in Nicotiana benthamiana 16C leaves. I-A, GFP mRNA and small interfering (si)RNA levels at 6 days postinoculation (dpi) in agroinfiltrated tissues are indicated above the images. A strong decrease of GFP mRNA and an increase of siRNA accumulation relative to the control are observed in the presence of hopX1 at 6 dpi, indicating enhancement of the GFP silencing by HopX1. Expression of viral suppressors P19 and P38 alone relieves silencing and hopX1 does not counteract this effect; GFP mRNA and siRNA levels in agroinfiltrated tissues are indicated above the images. I-B, Quantification (using the ImageJ program) of siRNA levels. In the presence of hopX1, the GFP siRNA level is increased approximately threefold compared with the empty vector control. II-A, GFP mRNA and siRNA levels at 6 dpi in agroinfiltrated tissues, as are indicated above the images. At 6 dpi, a decrease of GFP mRNA (below the control) and an increase of siRNA accumulation (above the control) was observed with hopAB1, indicating enhancement of GFP silencing. Expression of viral suppressors P19 and P38 alone or together with hopAB1 strongly increased GFP mRNA while strongly decreasing GFP siRNA levels. II-B, Quantification (using the ImageJ program) of siRNA levels. In the presence of hopAB1, the GFP siRNA level is increased approximately twofold compared with the empty vector control. III-A, GFP mRNA and siRNA levels in agroinfiltrated tissues as indicated below the images. GFP siRNAs appear at 5 to 6 dpi. Strong GFP siRNA accumulation is seen in leaves treated with hopX1 but not in those treated with hopX1m. III-B, Quantification of siRNA levels in hopX1- and hopX1m-treated leaves. 
because the agroinfiltrated areas developed chlorosis and were completely white under UV illumination by $3 \mathrm{dpi}$, followed by progressive tissue collapse at later days. With the $\Delta 4$ mutant, just like the WT HopAB2, GFP fluorescence clearly showed a silencing enhancement phenotype at 3 dpi compared with the empty vector control (later measurements were not recorded due to collapse of the agroinfiltrated tissue at $4 \mathrm{dpi}$, a phenotype that may be attributed to interaction of the Rsb domain present in this mutant with a hypothetical Fen homologue in $N$. benthamiana). The N-terminal domain of HopAB2 ( $\Delta 7$ mutant; Abramovitch et al. 2003) elicited strong tissue collapse by $3 \mathrm{dpi}$, which made the GFP fluorescence assay unreliable.

To overcome the progressive tissue collapse seen with the HopAB2 mutants, we took advantage of the similar domain structure of HopAB1 and HopAB2. We constructed a plant expression cassette (35S::AB1_CTD) expressing the C-terminal portion of HopAB1 (HopAB1 $1_{376-539}$ ) corresponding to the E3ubiquitin ligase domain (residues 388 to 553) and lacking the regions corresponding to the $\mathrm{N}$-terminal (Pto-interacting) and central (Rsb, Fen interacting) domains of HopAB2. The E3 Ub ligase regions of HopAB1 and HopAB2 are highly homologous ( $80 \%$ similarity, $64 \%$ identity), with only two single-residue relative deletions (T470 and P440 in the former are absent in the later). This construct did not elicit any visible symptoms in line $16 \mathrm{C}$ during the 8 - to 10 -day observation period and retained the strong silencing-enhancement phenotype of the fulllength HopAB1 protein (Fig. 4).

\section{Silencing enhancement by HopX1 is independent of its $\boldsymbol{R} 2$-mediated defense triggering function.}

According to Nimchuk and colleagues (2007), the HopX1 protein carries a putative catalytic triad strikingly homologous to the conserved catalytic triad domain of eukaryotic peptide: $\mathrm{N}$-glycosidases and a novel conserved $\mathrm{N}$-terminal domain. Both the catalytic triad and the $\mathrm{N}$-terminal domain are required for the gene-for-gene specific interaction of hopXl with the $R 2$ gene on resistant bean cultivars and the triggering of a celldeath response on Arabidopsis (Nimchuk et al. 2007). A sitedirect mutation in the catalytic triad (C182A) and a triple alanine substitution in the N-terminal conserved domain, corresponding to residues $\mathrm{R} 122$, N124, and D126, abolish the $R 2$ mediated defense response as well as the induction of the celldeath response on Arabidopsis spp. (Nimchuk et al. 2007). We tested these HopX1 mutants for their ability to affect GFP silencing in $N$. benthamiana 16C. None of the mutations had any significant effect on the ability of the HopX1 to enhance RNA silencing in our experiments (Fig. 5). This finding indicates that the silencing-enhancement activity of HopX1 is independent of its $R 2$ recognition ability.

\section{T3EP affect positively \\ the IsiRNA and nat-siRNA accumulation levels.}

Two studies (Katiyar-Agarwal et al. 2006, 2007) showed that an endogenous nat-siRNA, nat-siRNAATGB2 (ASRP 1957), and a novel class of small RNAs named lsiRNAs, 30 to 40 nucleotides long, sharing many common features with known siRNAs, are both specifically induced by the bacterial pathogen $P$. syringae carrying the avrRpt 2 gene. We studied the effect of: HopAB 1 and its truncation mutant retaining only the C-terminal domain, HopAB2 and its $\Delta 4$ (Rsb + C-terminal E3 ubiquitin ligase domain) and F489A mutant, HopX1 and its catalytic triad (C182A) and triple alanine substitution mutants on the endogenous lsiRNA and nat-siRNA accumulation in the efr-1 Arabidopsis Col-0 plants. The efr mutant sustained efficient transient transformation by Agrobacterium strains because it carried a mutation in EFR, the PAMP (bacterial EF-Tu)-recognition receptor, a receptor-like kinase which largely attenuates the
PAMP-triggered immunity of agroinfiltration (Zipfel et al. 2006) and, like the WT Col-0, does not develop necrosis with HopX1, HopAB1, or HopAB2. Agrobacterium strains carrying the $35 S:: h o p A B 1$, 35S::hopX1, and 35S::hopAB2 were examined here, along with Agrobacterium strains carrying the T3EP 35::avrRpt2 as an HR-triggering control for comparison following the methods described by Katiyar-Agarwal and associates (2006, 2007). We observed that HopAB1 and HopX1 could weakly induce both nat-siRNAATGB2 and AtlsiRNA-1 at 4 dpi (Fig. 6). The fold accumulation for lsi- and nat-siRNA levels compared with the empty vector controls was similar to what was seen for the GFP siRNA accumulation (Fig. 2). Likewise, Agrobacterium strains carrying the $35 S::$ hopAB2, 35S::hopAB2F489A (E3 ubiquitin ligase) mutant, 35S::hopAB2- $\Delta 4$ mutant, and $35 S:: h o p A B 2-\Delta 7$ mutant were examined. Surprisingly, the HopAB2-F489A mutant could still weakly induce both natsiRNAATGB2 and AtlsiRNA-1 (Supplementary Fig. S6), although the induction levels were much weaker than those by HopAB1 (Fig. 6) compared with the empty vector controls. These results show that HopX1, HopAB1, and HopAB2 affect positively the 1si- and nat-siRNA accumulation in efr-1 Arabidopsis without triggering the HR and that the actual accumulation of these siRNAs remained considerably lower than what is observed in the incompatible RPS2-AvrRpt2-mediated $P$. syringae pv. tomato-Arabidopsis interaction. We did not see a clear effect of HopF2 on the accumulation of lsi- and nat-siRNA (data not shown).

\section{Crown gall callus suppression by HopX1.}

Based on the findings of Dunoyer and associates (2006), we reasoned that it might be possible to interfere with crown gall formation by oncogenic agrobacteria by expressing T3EP that enhance silencing at grown gall infection sites. To test this hypothesis, we introduced the binary pART27-35S::hopX1 vector into the oncogenic A. tumefaciens A281 (Hood et al. 1986). Inoculations were carried out using this strain as well as $A$. $t u$ mefaciens A281 with and without pART27 (empty vector [EV]) as controls (Fig. 7A and $\mathrm{C}$, respectively). Four representative leaf petioles were inoculated with each strain and all experiments were repeated at least four times, with similar results. Tumor development was scored and photographed 28 dpi. Typical crown gall tumors were observed in all WT T-DNA and EV treatments (Fig. 7). In contrast, no tumors developed in $85 \%$ of the petioles inoculated with the A. tumefaciens A281 carrying the $35 S::$ hopX1 expression cassette (Fig. 7B). A mild necrosis was observed in the epidermis around the inoculation area with the agrobacteria carrying $35 S:: h o p X 1$. The same functional assay conducted with HopF2 and tumor formation gave 65 to $75 \%$ reduction of gall formation in tomato petioles (data not shown). The results suggest that transfer or expression of the 35S::effector cassettes carried on the binary T-DNA vector in the infected cells may interfere with the establishment of the antisilencing state proposed to be essential for crown gall development (Dunoyer et al. 2006).

\section{DISCUSSION}

Our studies provide new evidence that phytobacterial pathogen T3EP manipulate the plant siRNA pathways. By choosing effectors that do not elicit HR or other macroscopic symptoms in $N$. benthamiana $16 \mathrm{C}$, we investigated their effects on RNA silencing pathways in the absence of ETI signaling or necrotic reactions elicited by effector-receptor functional recognition. Such effects were simply and conveniently monitored as changes in GFP fluorescence in agroinfiltrated leaves at appropriate time points along with appropriate controls and were confirmed at the molecular level by the detection of GFP-specific 
siRNA levels in agroinfiltrated $N$. benthamiana $16 \mathrm{C}$ leaf tissue. The HopX1, HopAB1/AB2, and HopF2 effectors gave the strongest enhancement of S-PTGS in the $N$. benthamiana line $16 \mathrm{C}$ among several effectors that were surveyed and, for this reason, they were studied in some detail. In addition to increasing GFP siRNAs, these T3EP positively affected nat-siRNA and lsiRNA levels in noncollapsed agroinfiltrated leaves of efr Arabidopsis thaliana. However, the induction of nat-siRNA and lsiRNA was very weak compared with what is seen in HRinducing experimental settings (Fig. 6) (Katiyar-Agarwal et al. 2006, 2007). The accelerated quenching of GFP fluorescence cannot be attributed to tissue collapse caused by the effector in the agroinfiltrated tissue. However, it is conceivable that high intracellular effector accumulation levels generally attained by agroinfiltration (Twyman et al. 2003) may cause other types of stress in the cells or may set in motion events that are not manifested as phenotypic or molecular-level responses studied thus far. Although the exact mechanism of effector involvement in silencing requires further study, the enhancement effects seen in the absence of ETI signaling points to a potential role of silencing in compatible Pseudomonas spp.-plant interactions.

The involvement of various gene-silencing pathways in the context of $P$. syringae-plant interactions has been documented in several studies and the subject was recently reviewed (Katiyar-Agarwal and Jin 2010). For example, several Arabidopsis endogenous siRNAs are induced by $P$. syringae pv. tomato carrying a T3EP (AvrRpt2) originating from the heterologous pathogen $P$. syringae pv. pisi (Katiyar-Agarwal et al. 2006, 2007). This effector is recognized by the cognate coiledcoil NBS-LRR $R$ gene receptor RPS2, triggering ETI in the form of HR. In their study, effector delivery was via the native Pseudomonas T3SS. In the study by Navarro and associates (2008), T3EP derived from $P$. syringae pv. tomato DC3000 suppressed miR393a and miR393b RNA transcription, accumulation, and function in Arabidopsis following agrodelivery. Our findings extend these studies, by demonstrating the ability of $P$. syringae T3EP HopX1, HopAB1/AB2, and HopF2 to enhance the siRNA accumulation levels in another model plant, $N$. benthamiana, following agrodelivery.

The fact that silencing enhancement by the T3EP studied was seen in the absence of any macroscopically visible effect (other than on GFP fluorescence) in the $N$. benthamiana $16 \mathrm{C}$ leaves suggests that this activity is not related to functional effector-host $\mathrm{R}$ receptor recognition necessary for HR-PCD or ETI signaling. In an effort to further separate the plant receptor-recognition function from silencing enhancement, we used genetic truncations or site-directed mutants of the effectors investigated in this study. With the HopAB1, the C-terminal domain alone and the Rsb+C-terminal domains, respectively, were fully capable of GFP silencing enhancement. However, this ability could not be linked to or separated from the protein's E3 ubiquitinating ligase activity per se.

Dunoyer and colleagues (2006) showed that knockout mutants of A. thaliana affected in genes coding for protein components of the silencing machinery ( $r d r 6$ loss-of-function plants), as well as transgenic plants expressing the p38 viral silencing suppressor, were hypersusceptible to crown gall tumor formation by WT agrobacteria In earlier studies, Escobar and associates $(2001,2002)$ obtained broad-spectrum crown gall resistance in Arabidopsis thaliana) and tomato (Lycopersicon esculentum) and English (Persian) walnut (Juglans regia) through the induction of PTGS by expressing self-complementary constructs designed to initiate PTGS for T-DNA genes (iaaM and ipt). Accordingly, we hypothesized that the T3EP capable of silencing enhancement might impart crown gall resistance in plants. We found that the presence of the $35 S:$ :
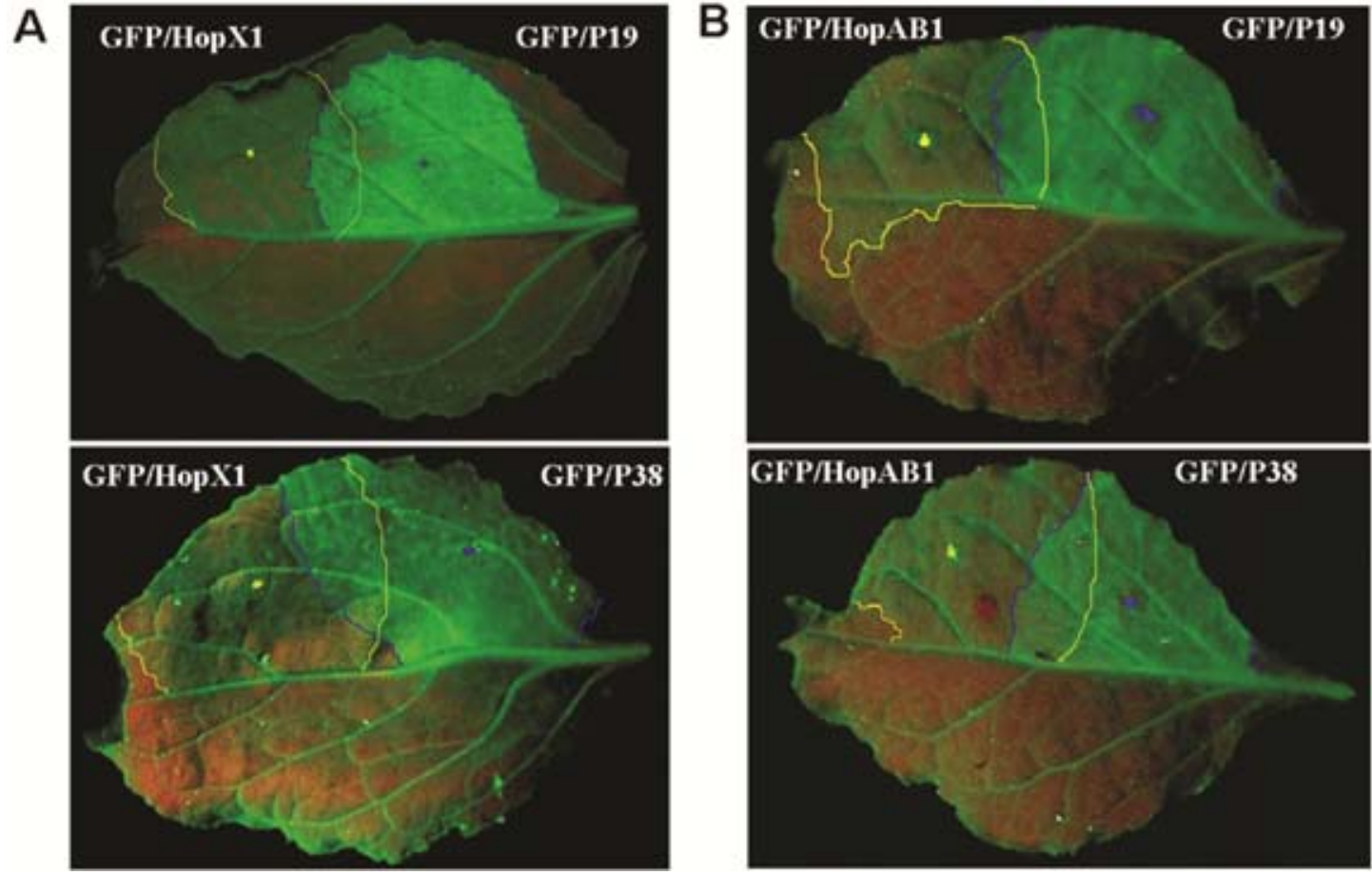

Fig. 3. Overlap infiltration assay (Chakravarthy et al. 2009; Oh and Collmer 2005) with agrobacteria carrying expression cassettes for hopX1 or hopAB1 and for viral silencing suppressor P19 or P38. Mixtures (1:1) of agrobacteria carrying separate expression cassettes for green fluorescent protein (GFP), type III effector proteins (HopX1 or HopAB1), and the viral silencing suppressors P19 or P38, each under the Cauliflower mosaic virus 35S promoter, were infiltrated in Nicotiana benthamiana 16C leaves in combinations indicated above the images and photographed 6 days postinoculation. The type III effector silencing enhancer phenotype on green fluorescent protein (GFP) accumulation is fully reversed (strong fluorescence in the overleaping co-infiltration area) by both viral suppressors. A, $N$. benthamiana $16 \mathrm{C}$ leaves infiltrated with $1: 1$ mixtures of agrobacteria containing $35 S:: \mathrm{GFP} / 35 S::$ hopX1, and $35 S:: \mathrm{GFP} / 35 S::$ : P19 or $35 S:: G F P / 35 S:: P 38$. B, Leaves infiltrated with $1: 1$ mixtures of agrobacteria containing $35 S:: G F P / 35 S:: h o p A B 1$ and $35 S::$ GFP/35S::P19 or $35 S:: \mathrm{GFP} / 35 S:: \mathrm{P} 38$. Experiments were repeated at least eight times on separate $N$. benthamiana $16 \mathrm{C}$ plants with similar results. 
hopX1 and $35 S:: h o p F 2$ plant expression cassettes in WT A. tumefaciens A281 resulted in suppression of crown gall formation in the $N$. benthamiana and tomato petiole coinoculation assay. Crown gall callus suppression was also seen in stable $N$. benthamiana transformants expressing the $35 S::$ hopX1 cassette (N. Skandalis, A. Papanikolaou, P. F. Sarris, and N. J. Panopoulos, unpublished data). In a recent study, Ellendorff and associates (2009) showed that RNA-dependent gene silencing plays an active role in the defense of plants toward the fungal pathogen Verticillium dahliae, which colonizes the conducting vessels of the plant root system. They suggested that $V$. dahliae depends on an active PTGS to successfully colonize the host and incite vascular disease.

Our studies raise several other questions or themes for further investigation. First, does effector-mediated silencing enhancement occur at sufficiently early stages of Pseudomonas spp.plant interactions to promote virulence? Agroinfiltration assays take several days to give full expression of the transiently expressed transgenes and, in our experiments, the differences in the GFP fluorescence between effector-treated and control leaves were first observed at $3 \mathrm{dpi}$. This timing would appear to be sufficiently early for effector-enhanced silencing to play a role in productive pathogenesis. We carried out inoculations of
$N$. benthamiana with $P$. syringae pv. syringae $\mathrm{B} 728 \mathrm{a}\left(5 \times 10^{5}\right.$ $\mathrm{CFU} / \mathrm{ml}$ ) cassettes, both simultaneously and $24 \mathrm{~h}$ postinfiltration with agrobacteria carrying the HopX1, HopAB1, and HopF2 plant expression cassettes. These experiments did not produce conclusive results. However, recent studies (Guo et al 2009; Wilton et al 2010) showed that HopF2-expressing transgenic Arabidopsis supports higher populations of the compatible pathogen $P$. syringae pv. tomato DC 3000 at 4 and 3 dpi, respectively. Furthermore, expression of HopF2 in transgenic Arabidopsis plants compromised immunity to a necrotrophic fungal pathogen, Botrytis cinerea, as well as nonhost immunity to $P$. syringae pv. phaseolicola (Wu et al. 2011). Finally, host defense suppression function has also been previously reported for HopAB1/2 (Jackson et al. 1999; de Torres et al. 2006) and HopX1 (Guo et al. 2009; Jamir et al. 2004). Second, how do these T3EP engage the plant-silencing machinery in molecular terms and how does this influence the expression of genes involved in the suppression of the host defense mechanisms? Our experiments do not directly address this question. Third, how widespread are silencing-enhancing effectors in phytobacterial genomes, and do these pathogens rely on silencing enhancement as part of their virulence strategy? Bioinformatic searches in wholly or partially sequenced phytobacterial ge-

\section{A} Contr. E.V. / HopAB1 w.t.

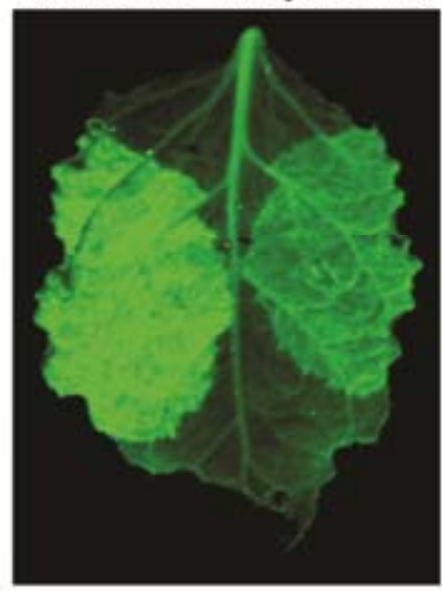

Contr. E.V. / HopAB1 CTD

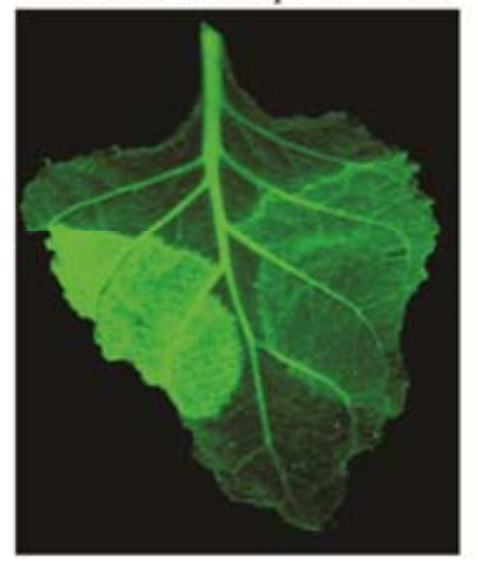

II Contr. E.V. / HopAB1 w.t.
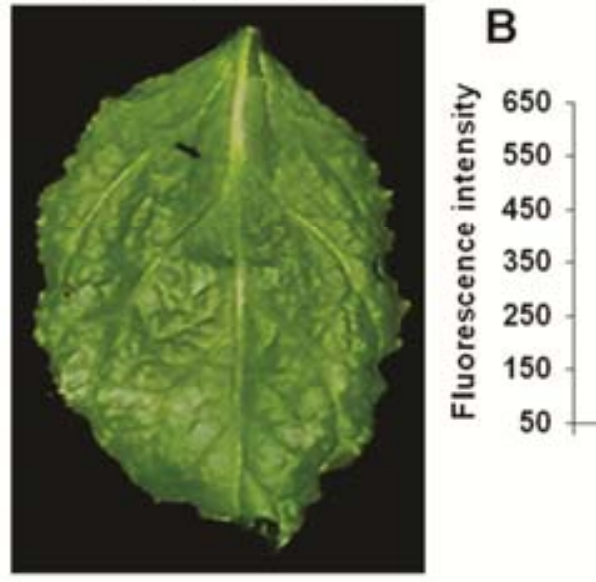

Average GFP fluorescence

Contr. E.V. / HopAB1 CTD

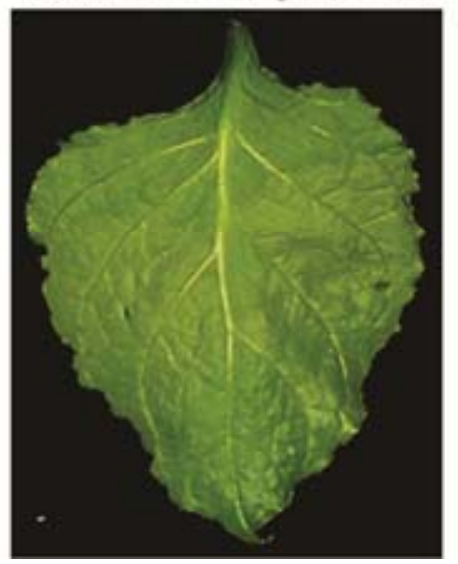

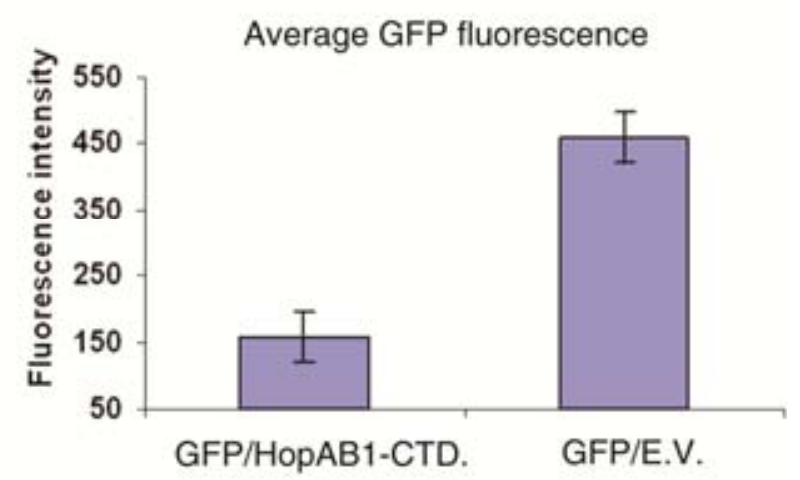

Fig. 4. Effect of transiently expressed hopAB1 wild type (w.t.) and hopAB1-CTD (HopAB1 $376-539)$ on green fluorescent protein (GFP) silencing in Nicotiana benthamiana $16 \mathrm{C}$ plants. hopAB1 w.t. and the hopAB1-CTD have been cloned under the transcription regulation of the $35 S$ Cauliflower mosaic virus promoter in the pBin-Hyg-Tx vector. A, GFP fluorescence assay. Mixtures $(1: 1)$ of agrobacteria carrying the expression constructs indicated above the images were infiltrated in $N$. benthamiana $16 \mathrm{C}$ leaves photographed at 5 days postinoculation (dpi) under UV (A-I) and visible (A-II) light. Agroinfiltration was carried out as described (Hamilton et al. 2002). GFP fluorescence was monitored 4, 5, and 6 dpi with a handheld long-wavelength UV lamp. B, Densitometric quantification of GFP fluorescence in infiltrated areas of leaves. Experiments were repeated at least 10 times on separate plants with similar results. 
nomes reveal the presence of multiple T3EP with homology to silencing enhancement-active T3E proteins studied here; for example, $P$. syringae pv. phaseolicola 1448 A possess both HpAB1 and HopF2 (as well as HopX1 but with a point mutation of unknown phenotypic significance). Finally, because the T3SS mediates many pathogenic, symbiotic, and commensal gramnegative prokaryote-eukaryote interactions, it would be interesting to investigate whether bacteria possessing a T3SS engage the RNA-silencing pathways in the general context of their interorganismal associations.

The identification of T3EP from plant-pathogenic bacteria has been based on a number of criteria: avirulence function tests (ability to restrict host range or to elicit HR on appropriate indicator plants), comparative genomic and bioinformatic analysis (homology to known effectors, linkage to T3SS genes or putative chaperones, T3SS-like regulation, T3SS secretion signals, or other characteristic motifs), T3SS-dependent secretion or translocation assays, and other in vivo genetic screens (Fujikawa et al. 2006; Grant et al. 2006; Nomura et al. 2006; Oh and Collmer, 2005). GFP fluorescence on $N$. benthamiana $16 \mathrm{C}$ and, perhaps, on other appropriate indicator plants can be easily scored; therefore, they might be considered as additional provisional candidate assays for possible effector function, if they are validated further.
A

Contr. E.V. / HopX1 w.t.

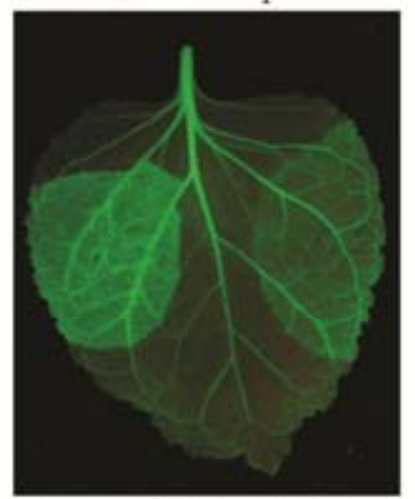

Contr. E.V./ HopX1 mut.I

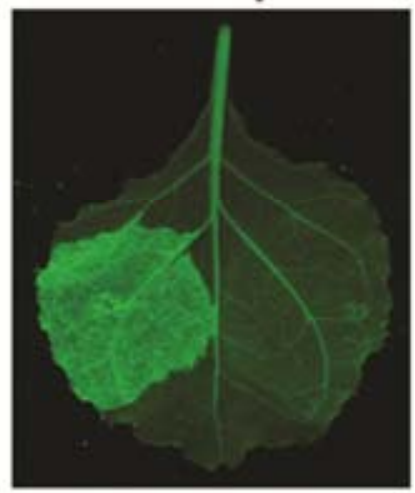

Contr. E.V. / HopX1 mut.II

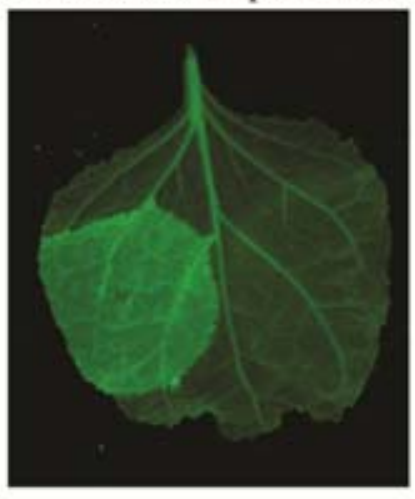

II

Contr. E.V./ HopX1 w.t.

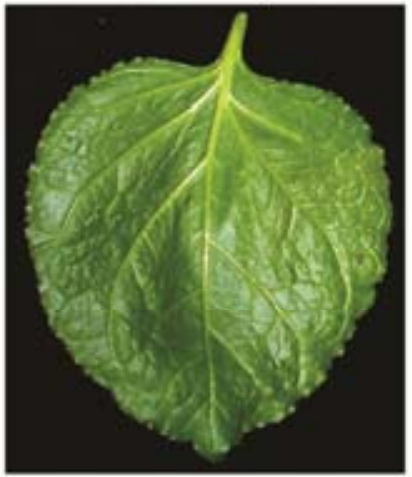

Contr. E.V. / HopX1 mut.I

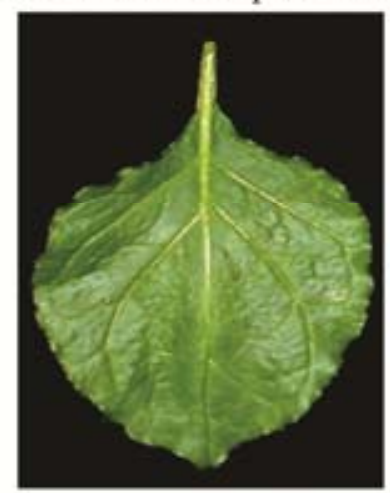

Contr. E.V. / HopX1 mut.II

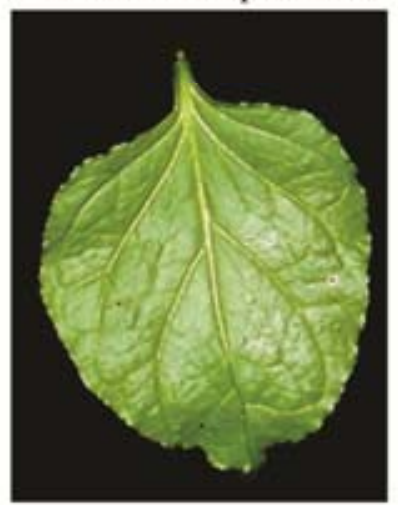

B

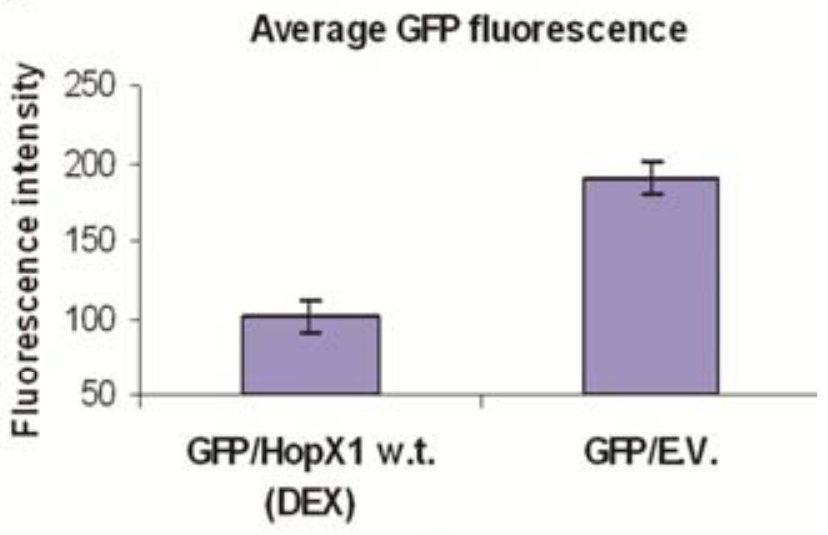

Average GFP fluorescence

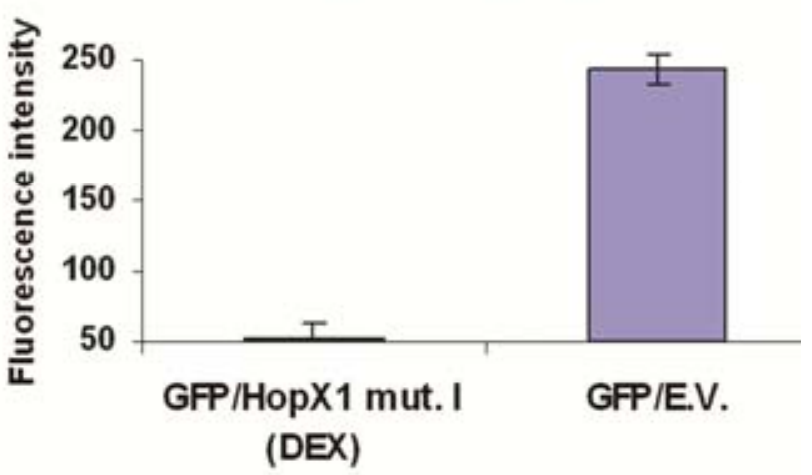

Average GFP fluorescence

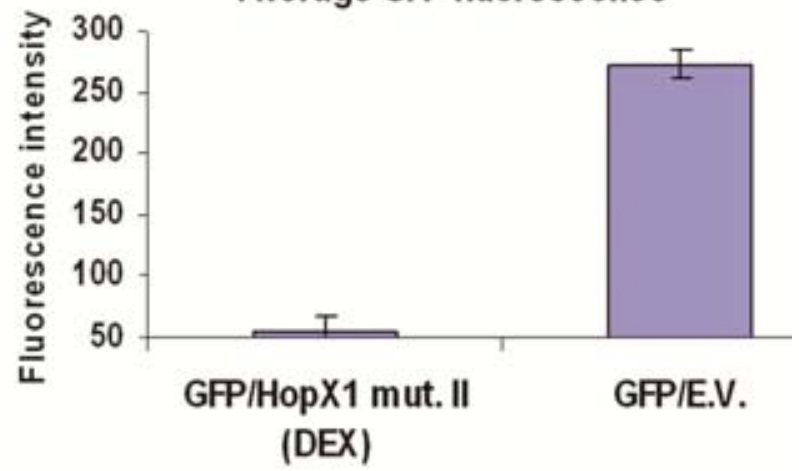

Fig. 5. Effect of transiently expressed hopX1 wild type (w.t.), hopX1 mutant 1 (N-terminal domain), and hopX1 mutant 2 (catalytic triad) alleles on green fluorescent protein (GFP) silencing in Nicotiana benthamiana 16C plants. hopX1 w.t. and the two mutants have been cloned under the transcription regulation of a dexamethasone (DEX)-inducible promoter in the pTA7002 vector. A, GFP fluorescence assay. Mixtures (1:1) of agrobacteria carrying the expression constructs indicated above the images were infiltrated in $N$. benthamiana 16C leaves photographed at 6 days postinoculation (dpi) under UV (A-I) and visible (A-II) light. Agroinfiltration was carried out as described (Hamilton et al. 2002). GFP fluorescence was monitored 4 and 6 dpi with a handheld longwavelength UV lamp. B, Densitometric quantification of GFP fluorescence in infiltrated areas of leaves. Experiments were repeated at least 10 times on separate plants with similar results. 


\section{MATERIALS AND METHODS}

Plant materials.

$N$. benthamiana line 16C and WT $N$. benthamiana plants were grown in a glasshouse under controlled light and temperature. $N$. benthamiana $16 \mathrm{C}$ was kindly donated by D. Baulcombe, the Sainsbury Laboratory, John Innes Centre, Norwich, U.K. The Arabidopsis thaliana efr-1 seed, as well as the Arabidopsis thaliana ecotype Col-O seed, were donated by C. Zipfel (Zipfel et al. 2006).

\section{Bacterial strains and vector construction.}

All T-DNA constructs were cloned in binary vectors and were introduced into $A$. tumefaciens $\mathrm{C} 58 \mathrm{C} 1$ by electroporation as described (Nagel et al. 1990). The virulent A. tumefaciens A281 strain was used for the agrosuppression assays (Kamoun et al. 2003). Dexamethasone inducible constructs for HopX1 WT and HopX1 mutants is described by Nimchuk and associates (2007). Other plant transformation vectors used in this study for effector delivery were constructed by cloning separate polymerase chain reaction products, with restriction sites added to the appropriate primers, into the vector polylinker (Supplementary Table S1) downstream from the CaMV 35S promoter. These vectors were



Fig. 6. Effect of transient expression of cassettes for hopAB1, HopAB1-C terminal domain (residues 376-539), HopX1, and HopX1-A domain and catalytic triad mutants and HopAB1-C terminal domain (residues 376 to 539) on the 1siRNA and nat-siRNA accumulation in agroinfiltrated efr-1 Arabidopsis plants. For these experiments, Pseudomonas syringae pv. tomato DC3000 carrying the avrRpt2 gene was used as a positive technical control for comparison.
pART27/hopX1 (effector gene obtained from $P$. syringae pv. tomato DC3001) (Landgraf et al. 2006), pART27/hopXIm, pBin-Hyg-Tx/hopAB1, pBin-A7-Tx/hopAB1-CTD, pBin-A7Tx/hopAB1-NTD, and pART27/hopF2 (Supplementary Data).

\section{Agrobacterium transient expression assays}

in $N$. benthamiana.

A. tumefaciens $\mathrm{C} 58 \mathrm{C} 1$ strains carrying the binary vector constructs were grown and prepared for transient expression as described by Koscianska and associates (2005) and Kalantidis and associates (2006). For monitoring the expression or silencing of GFP, a handheld 100-W long-wavelength UV lamp (B1000AP; Ultraviolet Products) was used, and a Nikon COOLPIX 990 digital camera was used for photography. Leaf RNA extractions were performed in samples flash-frozen and ground in a porcelain mortar under liquid nitrogen. For the GFP co-agroinfiltration assays, the pBIN-35S::mgfp5-ER construct (J. Hasellof, MRC Cambridge) was transferred to A. tumefaciens $\mathrm{C} 58 \mathrm{C} 1$ by triparental mating using Escherichia coli HB101 (pRK2013) as the conjugation helper (Bevan 1984). For silencing-suppression assays, two viral silencing suppressors were used: the TCV silencing suppressor p38 (viral coat protein) cloned in the Agrobacterium vector pBin61 (Thomas et al. 2003) and the CymRSV silencing suppressor p19 cloned in the Agrobacterium vector pBI 121.1 (Havelda et al. 2003).

\section{Agrobacterium-mediated transient expression in Arabidopsis thaliana.}

Agrobacterium-mediated transient transformation was performed in the Arabidopsis thaliana efr mutant as previously described (Zipfel et al. 2006). Briefly, 4-week-old efr mutants were syringe-infiltrated with A. tumefaciens $\mathrm{C} 58 \mathrm{C} 1$ strain carrying T3EP cDNAs driven by the $35 S$ promoter. The same strain carrying the empty vector, including the $35 \mathrm{~S}$ promoter, was used as a negative control. Agrobacteria were grown for 2 days at $28^{\circ} \mathrm{C}$ and resuspended in an Agrobacterium induction medium containing acetosyringone at $50 \mu \mathrm{g} / \mathrm{ml}$ as described (Koscianska et al. 2005). The bacteria were then left in the dark with mild shaking (room temperature) for 5 to $7 \mathrm{~h}$ in induction medium and further resuspended into MES $(0.1 \mathrm{~g} /$ liter $) / \mathrm{MgCl}_{2}(10 \mathrm{mM})$ to an optical density at $600 \mathrm{~nm}$ of 0.4 before syringe infiltration. Samples were collected at 4 days postinfiltration.

mRNA and small RNA gels and Northern blot analysis.

Small RNA and mRNA gels and blot analyses were done as described (Kalantidis et al. 2006; Koscianska et al. 2005), using $m$-gfp 4 -ER or an effector gene-derived random priming
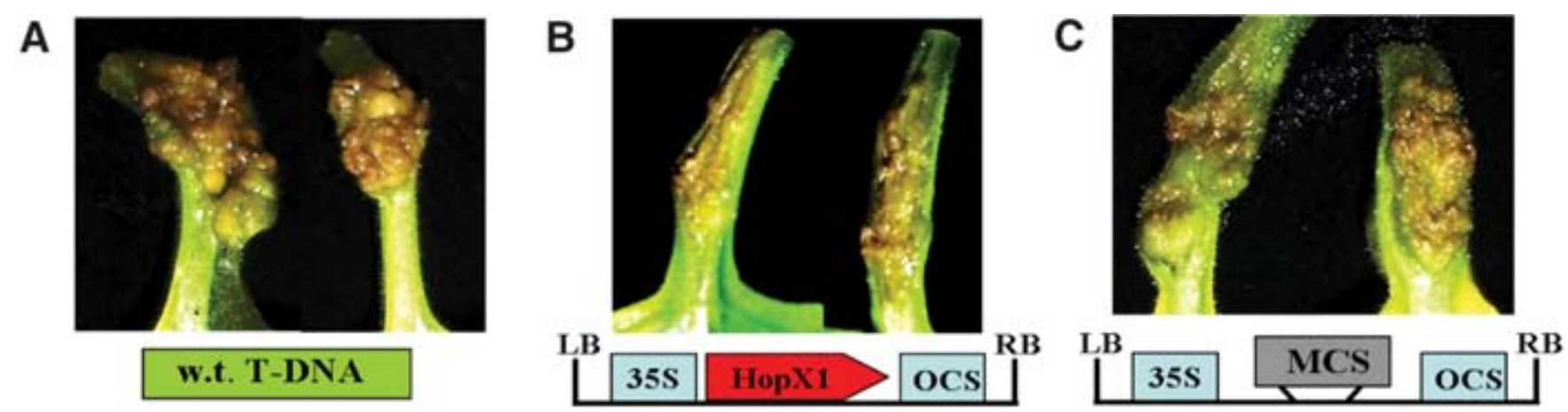

Fig. 7. Inhibition of crown gall tumor development in petioles of Nicotiana benthamiana. Petioles of wild-type (w.t.) N. benthamiana leaves were photographed 28 days after inoculation with: A, Agrobacterium tumefaciens A281 (A. tumefaciens C58C1 [pTiBo542], induces crown gall tumors); B, A. tumefaciens A281 carrying the 35 S::hopX1 cassette; and C, A. tumefaciens A281 carrying pART27 (empty vector [EV]) used as negative control. The relevant elements of the T-DNAs are schematically drawn below the photographs. 35S refers to the Cauliflower mosaic virus $35 S$ promoter and OCS refers to the octopine synthase gene transcription terminator region. Four petioles were inoculated for each treatment and all experiments were repeated at least four times. Crown gall tumors were observed in all $\mathbf{A}$, w.t. Ti and $\mathbf{C}, \mathrm{EV}$ treatments. In contrast, no gall formation was observed in $80 \%$ of the petioles inoculated with A. tumefaciens A281 currying the $35 S::$ hopX1 expression cassette. 
radiolabeled probe. Total RNA was extracted from pooled leaf samples of three different plants, ground in liquid nitrogen using a Trizol reagent (Invitrogen) according to the manufacturer's protocol. Northern analysis of low molecular weight RNAs was performed with 50 to $60 \mu \mathrm{g}$ of total RNA, measured in a NanoDrop instrument (Thermo Scientific NanoDrop 1000 Spectrophotometer) as described (Akbergenov et al. 2006). Ethidium bromide staining and visualization of total RNA bands in agarose RNA gels was used to monitor the loading of RNA samples.

\section{Agrobacterium dexamethasone-inducible transient expression assays.}

Transient transformation assays were performed, as previously described, using $30 \mu \mathrm{M}$ dexamethasone (Nimchuk et al. 2007). $N$. benthamiana $16 \mathrm{C}$ plants were scored for phenotypes 20 and $48 \mathrm{~h}$ postinduction.

\section{Callus agrosuppression assay.}

A binary vector carrying $35 S:: h o p X 1$ was introduced into a WT A. tumefaciens A281 (a C58C1 derivative carrying the WT Ti plasmid pTiBo542) which induces crown gall tumors (Hood et al. 1986). WT $N$. benthamiana plants (approximately 5 weeks old) were used for the agrosuppression assay, as described (Kamoun et al. 2003). Plants were cultured and maintained in a greenhouse under controlled temperature and light conditions. Inoculations were performed on the upper (younger) five leaves by dipping a wooden sterile toothpick into a bacterial colony and wounding the leaves twice along the petiole. Symptoms were scored daily and typically started to develop within $12 \mathrm{dpi}$. All experiments were repeated at least four times, and a minimum of three plants were used per experiment.

\section{Image analysis.}

Image and pixel analyses for GFP density, siRNAs, and mRNA quantification were performed with ImageJ $1.37 \mathrm{v}$ (developed at the United States National Institutes of Health and available online). Photography and densitometry details are given in the captions of Figures 1 and 7.

\section{ACKNOWLEDGMENTS}

We thank J. Haseloff for the mGFP4 plasmid, D. Baulcombe for the $N$. benthamiana 16C line, J. Burgyan for the p19 plasmid, A. Maulea for the p38 plasmid, J. Dangl for dexamethasone-inducible hopX1 plasmids, J. Mansfield for the P. syringae pv. tomato DC3001 strain, D. Cuppels for the P. syringae pv. tomato DC3000 strain, G. Martin for the WT avrPtoB, $\triangle 4$, NTD, and F489A mutants, and P. Moschou for his help with the use of radioactive materials. This research was supported in part by Secretariat for Research and Technology grants 05NON-EU-170 and PENED87503ED to N. Panopoulos, ESPA 09FR17 to K. Kalantidis, and National Institutes of Health grant R01 GM093008 and a National Science Foundation Career Award MCB-0642843 to H. Jin.

\section{LITERATURE CITED}

Abramovitch, R. B., and Martin, G. B. 2005. AvrPtoB: A bacterial type III effector that both elicits and suppresses programmed cell death associated with plant immunity. FEMS (Fed. Eur. Microbiol. Soc.) Microbiol. Lett. 245:1-8.

Abramovitch, R. B., Kim, Y. J., Chen, S., Dickman, M. B., and Martin, G. B. 2003. Pseudomonas type III effector AvrPtoB induces plant disease susceptibility by inhibition of host programmed cell death. EMBO (Eur. Mol. Biol. Organ.) J. 22:60-69.

Akbergenov, R., Si-Ammour, A., Blevins, T., Amin, I., Kutter, C. Vanderschuren, H., Zhang, P., Gruissem, W., Meins, F., Jr., Hohn, T. and Pooggin, M. M. 2006. Molecular characterization of geminivirusderived small RNAs in different plant species. Nucleic Acids Res. 34:462-471.

Alfano, J. R., and Collmer, A. 2004. Type III secretion system effector proteins: Double agents in bacterial disease and plant defense. Annu. Rev. Phytopathol. 42:385-414.

Bevan, M. 1984. Binary Agrobacterium vectors for plant transformation. Nucleic Acids Res. 12:8711-8721.

Chakravarthy, S., Velásquez, A. C., and Martin, G. B. 2009. Assay for pathogen-associated molecular pattern (PAMP)-triggered immunity (PTI) in plants. JoVE 31. doi:10.3791/1442. Published online.

Chisholm, S. T., Coaker, G., Day, B., and Staskawicz, B. J. 2006. Hostmicrobe interactions: Shaping the evolution of the plant immune response. Cell 124:803-814.

Dangl, J. L., and Jones, J. D. G. 2001. Plant pathogens and integrated defence responses to infection. Nature 411:826-833.

Dunoyer, P., Himber, C., and Voinnet, O. 2006. Induction, suppression and requirement of RNA silencing pathways in virulent Agrobacterium tumefaciens infections. Nat. Genet. 38:258-263.

Ellendorff, U., Fradin, E. F., de Jonge, R., and Thomma, B. P. H. J. 2009 RNA silencing is required for Arabidopsis defense against Verticillium wilt disease. J. Exp. Bot. 60:591-602.

Ellis, J. G., Dodds, P. N., and Lawrence, G. J. 2007. Flax rust resistance gene specificity is based on direct resistance-avirulence protein interactions. Annu. Rev. Phytopathol. 45:289-306.

Escobar, M. A., Civerolo, E. L., Summerfelt, K. R., and Dandekar, A. M. 2001. RNAi-mediated oncogene silencing confers resistance to crown gall tumorigenesis. Proc. Natl. Acad. Sci. U.S.A. 98:1343713442.

Escobar, M. A., Leslie, C. A., McGranahan, G. H., and Dandekar, A. M. 2002. Silencing crown gall disease in walnut (Juglans regia L.). Plant Sci. 163:591-597.

Espinosa, A., and Alfano, J. R. 2004. Disabling surveillance: Bacterial type III secretion system effectors that suppress innate immunity. Cell. Microbiol. 6:1027-1040.

Fahlgren, N., Howell, M. D., Kasschau, K. D., Chapman, E. J, Sullivan, C. M., Cumbie, J. S., Givan, S. A., Law, T. F., Grant, S. R., Dangl, J. L., Carrington, J. C. 2007. High-throughput sequencing of Arabidopsis microRNAs: Evidence for frequent birth and death of MIRNA genes. PLoS ONE 2:e219. doi:10.1371/journal.pone.0000219. Published online.

Flor, H. H. 1947. Inheritance of reaction to rust in flax. J. Agric. Res. 74:241262.

Fujikawa, T., Yamashita, T., and Tsuyumu, S. J. 2006. Hypersensitive response suppression by type III effectors of plant pathogenic bacteria. Gen. Plant Pathol. 72:176-179.

Gohre, V., and Robatzek, S. 2008. Breaking the barriers: Microbial effector molecules subvert plant immunity. Annu. Rev. Phytopathol. 46:189215.

Grant, S. R., Fisher, E. J., Chang, J. H., Mole, B. M., and Dangl, J. L. 2006. Subterfuge and manipulation: Type III effector proteins of phytopathogenic bacteria. Annu. Rev. Microbiol. 60:425-449.

Guo, H. S., and Ding, S. W. 2002. A viral protein inhibits the long range signalling activity of the gene silencing signal. EMBO (Eur. Mol. Biol. Organ.) J. 21:398-307.

Guo, M. Tian, F., Wamboldt, Y., and Alfano J. R. 2009. The majority of the Type III effector inventory of Pseudomonas syringae pv. tomato DC3000 can suppress plant immunity. Mol. Plant-Microbe Interact. 22:1069-1080.

Hamilton, A. J., Voinnet, O., Chappell, L., and Baulcombe, D. C. 2002 Two classes of short interfering RNA in RNA silencing. EMBO (Eur. Mol. Biol. Organ.) J. 21:4671-4679.

Hauck, P., Thilmony, R., and He, S. Y. 2003. A Pseudomonas syringae type III effector suppresses cell wall-based extracellular defense in susceptible Arabidopsis plants. Proc. Natl. Acad. Sci. U.S.A. 100:85778582

Havelda, Z., Hornyik, C., Crescenzi, A., and Burgyan, J. 2003. In situ characterization of Cymbidium Ringspot Tombusvirus infection-induced posttranscriptional gene silencing in Nicotiana benthamiana. J. Virol. 77:6082-6086.

He, P., Shan, L., Lin, N-C., Martin, G. B., Kemmerling, B., Nürnberger, T., and Sheen, J. 2006. Specific bacterial suppressors of MAMP signaling upstream of MAPKKK in Arabidopsis innate immunity. Cell 125:563575.

Hood, E. E., Helmer, G. L., Fraley, R. T., and Chilton, M. D. 1986. The hypervirulence of Agrobacterium tumefaciens A281 is encoded in a region of pTiBo542 outside of T-DNA. J. Bacteriol. 168:1291-1201.

Huang, H.-C., Sshuurink, R., Denny, T. P., Atkinson, M. M., Baker, C. J. Yucel, I., Hutcheson, S. W., and Collmer, A. 1988. Molecular cloning of a Pseudomonas syringae pv. syringae gene cluster that enables Pseudomonas fluorescens to elicit the hypersensitive response in tobacco plants. J. Bacteriol. 179:4748-4756.

Inoue, Y., and Takikawa, Y. 1999. Investigation of repeating sequences in hrpL neighboring region of Pseudomonas syringae strains. Ann. Phytopathol. Soc. Jpn. 65:100-109. 
Jackson, R. W., Athanassopoulos, E., Tsiamis, G., Mansfield, J. W., Sesma, A., Arnold, D. L., Gibbon, M. J., Murillo, J., Taylor, J. D., and Vivian, A. 1999. Identification of a pathogenicity island, which contains genes for virulence and avirulence, on a large native plasmid in the bean pathogen Pseudomonas syringae pathovar phaseolicola. Proc. Natl. Acad. Sci. U.S.A. 96:10875-10880.

Jamir, Y., Guo, M., Oh, H.-S., Petnicki-Ocwieja, T., Chen, S., Tang, X., Dickman, M. B., Collmer, A., and Alfano, J. R. 2004. Identification of Pseudomonas syringae type III effectors that can suppress programmed cell death in plants and yeast. Plant J. 37:554-565.

Janjusevic, R., Abramovitch, R. B., Martin, G. B., and Stebbins, C. E. 2006. A bacterial inhibitor of host programmed cell death defenses is an E3 ubiquitin ligase. Science 311:222-226.

Jones, J. D. G., and Dangl, J. L. 2006. The plant immune system. Nature 444:323-329.

Kalantidis, K., Tsagris, M., and Tabler, M. 2006. Spontaneous short-range silencing of a GFP transgene in Nicotiana benthamiana is possibly mediated by small quantities of siRNA that do not trigger systemic silencing. Plant J. 45:1006-1016.

Kamoun, S., Hamada, W., and Huitema, E. 2003. Agrosuppression: A bioassay for the hypersensitive response suited to high-throughput screening. Mol. Plant-Microbe Interact. 16:7-13.

Katiyar-Agarwal, S., Morgan, R., Dahlbeck, D., Borsani, O., Villegas, A., Jr., Zhu, J.-K., Staskawicz, B. J., and Jin, H. 2006. A pathogen-inducible endogenous siRNA in plant immunity. Proc. Natl. Acad. Sci. U.S.A. 103:18002-18007.

Katiyar-Agarwal, S., Gao, S., Vivian-Smith, A., and Jin, H. 2007. A novel class of bacteria-induced small RNAs in Arabidopsis. Genes Dev. 21:3123-3134.

Katiyar-Agarwal, S., and Jin, H. 2010. Role of small RNAs in host-microbe interactions. Annu. Rev. Phytopathol. 48:225-246.

Koscianska, E., Kalantidis, K., Wypijewski, K., Sadowski, J., and Tabler, M. 2005. Analysis of RNA silencing in agroinfiltrated leaves of Nicotiana benthamiana and Nicotiana tabacum. Plant. Mol. Biol. 59:647-661.

Landgraf, A., Wingart, H., Tsiamis, G., and Boch, J. 2006. Different versions of Pseudomonas syringae pv. tomato DC3000 exist due to the activity of an effector transposon. Mol. Plant Pathol. 7:355-364.

Mudgett, M. B. 2005. New insights to the function of phytopathogenic bacterial type III effectors in plants. Annu. Rev. Plant Biol. 56:509-531.

Nagel, R., Elliot, A., Masel, A., Birch, R. G., and Manners, J. M. 1990 Electroporation of binary Ti plasmid vector into Agrobacterium tumefaciens and Agrobacterium rhizogenes. FEMS (Fed. Eur. Microbiol. Soc.) Microbiol. Lett. 67:325-328.

Navarro, L., Dunoyer, P., Jay, F., Arnold, B., Dharmasiri, N., Estelle, M. Voinnet, O., and Jones, J. D. G. 2006. A plant miRNA contributes to antibacterial resistance by repressing auxin signaling. Science 312:436-439.

Navarro, L., Jay, F., Nomura, K., He, S. Y., and Voinnet, O. 2008. Suppression of the microRNA pathway by bacterial effector proteins. Science 321:964-967.

Nicaise, V., Roux, M., and Zipfel, C. 2009. Recent advances in PAMPtriggered immunity against bacteria: Pattern recognition receptors watch over and raise the alarm. Plant Physiol. 150:1638-1647.

Nimchuk, L. Z., Fisher, E. J., Desveaux, D., Chang, J. H., and Dangl, J. L. 2007. The HopX (AvrPphE) Family of Pseudomonas syringae type III Effectors require a catalytic triad and a novel $\mathrm{N}$-terminal domain for function. Mol. Plant-Microbe Interact. 20:346-357.

Nomura, K., Melotto, M., and He, S. Y. 2005. Suppression of host defense in compatible plant-Pseudomonas syringae interactions. Curr. Opin. Plant Biol. 8:361-368.

Nomura, K., DebRoy, S., Lee, Y. H., Pumplin, N., Jones, J., and He, S. Y.
2006. A bacterial virulence protein suppresses host innate immunity to cause plant disease. Science 313:220-223.

Oh, S. H., and Collmer, A. 2005. Basal resistance against bacteria in Nicotiana benthamiana leaves is accompanied by reduced vascular staining and suppressed by multiple Pseudomonas syringae type III secretion system effector proteins. Plant J. 44:348-359.

Peet, R. C., Lindgren, P. B., Willis, D. K., and Panopoulos, N. J. 1986. Identification and cloning of genes involved in phaseolotoxin production by Pseudomonas syringae pv. phaseolicola. J. Bacteriol. 166:1096-1105.

Rosebrock, T. R., Zeng, L., Brady, J. J., Abramovitch, R. B., Xiao, F., and Martin, G. B. 2007. A bacterial E3 ubiquitin ligase targets a host protein kinase to disrupt plant immunity. Nature 448:370-374.

Ruiz, M. T., Voinnet, O., and Baulcombe, D. C. 1998. Initiation and maintenance of virus-induced gene silencing. Plant Cell 10:937-946.

Tampakaki, .A. P., Skandalis, N., Gazi, A. D., Sarris, P. F., Bastaki, M. N. Charova, S. N., Kokkinidis, M., and Panopoulos, N. J. 2010. Playing the harp: Evolution of our understanding of the bacterial hrp genes. Annu. Rev. Phytopathol. 48:347-370.

Thomas, L. C., Leh, V., Lederer, C., and Maulea, A. J. 2003. Turnip crinkle virus coat protein mediates suppression of RNA silencing in Nicotiana benthamiana. Virology 306:33-41.

Tsiamis, G., Mansfield, J. W., Hockenhull, R., Jackson, R. W., Sesma, A., Athanassopoulos, E., Bennett, M. A., Stevens, C., Vivian, A., Taylor, J. D., and Murillo, J. 2000. Cultivar-specific avirulence and virulence functions assigned to avrPphF in Pseudomonas syringae pv. phaseolicola, the cause of bean halo-blight disease. EMBO (Eur. Mol. Biol. Organ.) J. 19:3204-3214.

Twyman, R. M., Stoger, E., Schillberg, S., Christou, P., and Fischer, R. 2003. Molecular farming in plants: Host systems and expression technology. Trends Biotechnol. 21:570-578.

Voinnet, O. 2001. RNA silencing as a plant immune system against viruses. Trends Genet. 17:449-459.

Voinnet, O., Lederer, C., and Baulcombe, D. C. 2000. A viral movement protein prevents spread of the gene silencing signal in Nicotiana benthamiana. Cell 103:157-167.

Wilton, M., Subramaniam, R., Elmore, J., Felsensteinera, C., Coaker, G., and Desveaux, D. 2010.The type III effector HopF2 $2_{\mathrm{pto}}$ targets Arabidopsis RIN4 protein to promote Pseudomonas syringae virulence. Proc. Natl. Acad. Sci. U.S.A. 107:2349-2354.

Wu, S., Lu, D., Kabbage, M., Wei, H. L., Swingle, B., Records, A. R., Dickman, M. B., He, P., and Shan, L. 2011. Bacterial effector HopF2 suppresses Arabidopsis innate immunity at the plasma membrane. Mol Plant Microbe Interact. 24:585-593.

Wulff, B. B., Chakrabarti A., and Jones, D. A. 2009. Recognitional specificity and evolution in the tomato-Cladosporium fulvum pathosystem. Mol. Plant Microbe Interact. 22:1191-1202.

Xiao, F., Ping He, P., Abramovitch, R. B., Dawson, J. E., Nicholson, L. K. Sheen, J., and Martin, G. B. 2007. The N-terminal region of Pseudomonas type III effector AvrPtoB elicits Pto-dependent immunity and has two distinct virulence determinants. Plant J. 52:595-614

Zipfel, C., Kunze, G., Chinchilla, D., Caniard, A., Jones, J. D. G., Boller, T., and Felix, G. 2006. Perception of the bacterial PAMP EF-Tu by the receptor EFR restricts Agrobacterium-mediated transformation. Cell 125:749-760

\section{AUTHOR-RECOMMENDED INTERNET RESOURCE}

United States National Institutes of Health Image $\mathbf{J}$ webpage: rsb.info.nih.gov/ij

Erratum published online on February 6, 2012

The authors also acknowledge that $\mathrm{K}$. Konstantinos is supported by a scholarship from the Greek State and the ESR-EU and ESPA (Heraclitus II, KA 3396). They thank the M. Tsagris labs for sharing chemicals and equipment and S. Zerveas, K. Nikos, and S. Kostas for technical assistance. 